\title{
Нестационарный влажностный режим жилых помещений и влияние на него сорбции паров воды
}

\author{
Е.В.Левин, НИИСФ РААСН, Москва \\ А.Ю.Окунев, НИИСФ РААСН, Москва
}

В статье рассмотрена одна из составляющих микроклимата в жилых помещениях - относительная влажность воздуха, величина которой устанавливается рядом нормативных документов. Для проведения исследований разработана физико-математическая модель, которая позволяет учитывать поступление и удаление водяного пара вместе с вентиляционным воздухом, внутренние источники водяного пара, включая дыхание человека, а также сорбцию и десорбцию на отделочных материалах. Расчёты выполнены для двухгодичного цикла эксплуатации жилой комнаты с учётом суточного и сезонного изменения температуры и влагосодержания наружного воздуха. В качестве исходных данных использованы архивные метеорологические данные для Москвы. При исследованиях рассмотрены три режима эксплуатации помещения: режим с постоянной вентиляцией; режим с постоянной вентиляцией и внутренними источниками выделения пара; режим с вентиляцией, источником пара и присутствием сорбции-десорбции. Показано, что в зимне-весенний период (декабрь-март) воздух в помещении может быть значительно пересушенным относительно нормативных требований, а в летнее время - значительно переувлажнённым. В результате расчётов установлено, что сорбция паров воды способна значительно сгладить суточные и сезонные колебания влажности и обеспечить нормативное влагосодержание в течение большей части года. Установлены критерии, которым должны соответствовать эффективные сорбирующие системы.

Ключевые слова: вентиляция, внутренний и наружный воздух, относительная влажность, температура, древесина, сорбция, диффузия.

Transient Humidity Conditions of Living Quarters and the Effect of Sorption of Water Vapour

E.V.Levin, NIISF RAACS, Moscow

A.Yu.Okunev, NIISF RAACS, Moscow

The article discusses one of the components of the microclimate inliving quarters-the relative humidity of air, the value of which is established by a number of regulatory documents. For research, a physical-mathematical model has been developed that allows taking into account the entry and removal of water vapor along with ventilation air, internal sources of water vapor, including human respiration, as well as sorption and desorption on finishing materials. The calculations were made for a two-year operation cycle of the living room, taking into account the daily and seasonal changes in temperature and moisture content of the outdoor air. Archive meteorological data for Moscow was used as the initial data. At researches three modes of operation of the room are considered: the mode with constant ventilation; the regime with constant ventilation and internal sources of steam; mode with ventilation, a source of steam and the presence of sorption-desorption processes. It is shown that in the winter-spring period (December - March) the air in the room can be significantly over-dried in relation to the regulatory requirements, and in the summertime significantly over-humidified. As a result of the calculations, it was established that the sorption of water vapor is able to significantly smooth out daily and seasonal fluctuations of humidity and ensure the normative moisture content during most of the year. The criteria for effective sorption systems are determined.

Keywords: ventilation, indoor and outdoor air, relative humidity, temperature, wood, sorption, diffusion.

Относительная влажность воздуха во внутренних помещениях жилых и общественных зданий является одним из главных факторов, влияющих на их эксплуатационные характеристики. Во-первых, уровень относительной влажности и её проникновение в ограждающие конструкции во многом определяют реальные теплозащитные и механические свойства ограждений [1-4]. Во-вторых, величина относительной влажности является одним из параметров микроклимата, обеспечивающего комфортные и безопасные условия нахождения человека в помещениях. Относительная влажность является нормируемой величиной и устанавливается положениями соответствующих документов, основными из которых в настоящее время являются ГОСТ 30494-2011. «Здания жилые и общественные. Параметры микроклимата в помещениях»; СанПиН 2.1.2.2645-10 «Санитарно-эпидемиологические правила и нормативы»; СП 60.13330.2012 «0топление, вентиляция и кондиционирование воздуха. Актуализированная редакция СНиП 41-01-2003» и СП 50.13330.2012 «Тепловая защита зданий. Актуализированная редакция СНиП 23-02-2003».

Так, согласно СП 50.13330.2012 по уровню относительной влажности, характерной для данного помещения, ему присваивается соответствующая категория влажностного режима эксплуатации - от сухого до мокрого. Например, если в интервале температуры в помещении от 12 до $24^{\circ} \mathrm{C}$ относительная влажность постоянно находится в пределах $50 \leq \varphi \leq 60 \%$, 
то такое помещение относится к категории с нормальным влажностным режимом. Если относительная влажность ниже $50 \%$, то такое помещение относится к категории с сухим влажностным режимом. Для жилых и общественных зданий ГОСТ 30494-2011 и СанПиН 2.1.2.2645-10 устанавливают требования к обеспечению величины относительной влажности и температуры, которые зависят от назначения помещения и периода года (холодный или тёплый). Например, для жилой комнаты в холодный период года оптимальная влажность должна находиться в пределах $30 \leq \varphi_{\text {opt }} \leq 45 \%$, а её допустимая величина не должна превышать $\varphi_{\max }=60 \%$. В тёплый период оптимальная и допустимая относительная влажность должна соответствовать условиям $30 \leq \varphi_{\text {opt }} \leq 60 \%$ и $\varphi_{\max }=$ $65 \%$ соответственно. Это означает, что может требоваться регулировка влажности (осушка или увлажнение) воздуха помещений, предназначенных для пребывания людей. Примечательно то, что устанавливаемый по ГОСТ 30494-2011 и СанПиН 2.1.2.2645-10 разброс по нормативным требованиям к влажности довольно широк, что, с одной стороны, облегчает задачу подготовки внутреннего воздуха для соответствия нормативной влажности, но, с другой стороны, затрудняет выбор конкретной величины влажности для проведения исследований и расчётов по её влиянию на теплозащитные и механические характеристики ограждающих конструкций. Например, при проведении теплотехнических расчётов, следуя ГОСТ 30494-2011 и СанПиН 2.1.2.2645-10, для холодного периода относительная влажность может быть положена как $\varphi=30 \%$ и ниже, так и $\varphi=60 \%$. При этом результаты по расчётам точки росы, её местоположению в толще утеплителя и другим теплотехническим характеристикам будут заметно отличаться, тем более совсем неизвестно, какая величина относительной влажности будет реализована на самом деле в процессе эксплуатации здания.

В принципе, при проектировании зданий и в процессе их эксплуатации наибольший интерес представляют не сами нормативные требования по влажности, которые, в конце концов, в случае необходимости будут обеспечены теми или иными техническими средствами и дополнительными энергозатратами, а прогнозируемый в здании влажностный режим, который может иметь место без использования специальных технических средств по регулированию влажности. Причём прогнозные данные для объективного учёта реальной обстановки должны относиться не к какому-либо короткому периоду времени, например, самая холодная пятидневка и др., а, как минимум, к полному годовому циклу эксплуатации помещений. На основе таких данных могут быть выполнены инженерные расчёты по оптимальной тепловой защите здания, а также разработаны технические мероприятия по обеспечению требуемых параметров микроклимата. К сожалению, среди доступных источников информации подобные данные практически отсутствуют.

Целью представленного исследования являлось определение детального влажностного режима в жилых помещениях в течение годового цикла их эксплуатации с учётом реального темпепратурно-влажностного состояния внешней атмосферы, наличия вентиляции и внутренних источников влаговыделения. В работе также рассмотрена возможность приближения влажностного режима к его нормативным показателям за счёт сорбции и десорбции влаги внутри помещения. Работа выполнена с помощью физико-математического моделирования нестационарного массопереноса для водяного пара в жилом помещении.

Физико-математическая модель, использованная в расчётах, учитывает нестационарный баланс водяного пара, поступающего и отводимого с вентиляционным воздухом, и внутренние источники водяного пара. В модели также рассмотрен дополнительный механизм, который может оказывать влияние на влажностный режим. Это наличие различного рода материалов, обладающих сорбционными свойствами по отношению к парам воды. В зависимости от текущего температурно-влажностного состояния окружающего воздуха такие материалы способны как поглощать, так и выделять пары воды и, в конце концов, возможно, оказывать демпфирующее воздействие на колебания относительной влажности. Необходимость учёта сорбционных свойств строительных материалов обсуждалась во многих работах (см., например, $[5 ; 6])$, но эти работы в основном касались изучения влияния сорбционного эффекта на увлажнение самого материала или оценок возможного равновесного влажностного режима помещения при наличии такого эффекта. Динамическое влияние сорбции в течение длительного периода времени эксплуатации помещений практически не изучено.

Исследования проведены на примере модельного жилого помещения (комнаты). Предполагается, что комната предназначена для постоянного пребывания одного человека. В качестве геометрических параметров комнаты выбраны

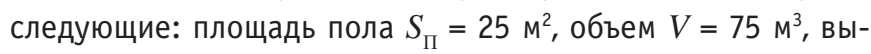
сота потолков $H=3 \mathrm{~m}$, площадь поверхности стен $S_{\text {ст }}=60$ $\mathrm{M}^{2}$. Подобная геометрия является типичной в современном жилищном строительстве.

В расчётах принято, что стены комнаты являются практически непроницаемыми для выхода водяного пара в наружный воздух, но их внутренняя поверхность может сорбировать и десорбировать пары воды. В качестве примера здесь можно иметь в виду наличие гигроскопических солей в бетонном стеновом материале (см., например, [5]), стены из дерева, обшивку стен ГКЛ, материалами на основе древесины и прочие. Кроме площади, характеристикой сорбирующего слоя будет являться его толщина $\delta$ (м) и наличие покрытия (например лакокрасночное или в виде плёнки, обои и др.), которое ограничивает массообмен между сорбирующим материалом и воздухом и характеризуется паропроницаемостью П, (кг/ $\left.\Pi \mathrm{\Pi a} / \mathrm{m}^{2} / \mathrm{c}\right)$.

Введём эксплуатационные характеристики рассматриваемой модельной комнаты. Пусть в ней в течение всего времени поддерживается постоянная температура $t_{\mathrm{B}}=+20^{\circ} \mathrm{C}$ и осу- 
ществляется постоянное вентилирование внешним воздухом. В помещении постоянно присутствует один человек. Будем считать, что основным назначением вентиляции является нормализация молекулярного состава воздуха в помещении по содержанию углекислого газа, кислорода и различного рода загрязнителям. В этом случае минимальные требования к потоку вентиляции составляют величину $Q \approx 30 \mathrm{~m}^{3} / 4 а \mathrm{c} /$ чел. При таком минимальном потоке воздуха концентрация кислорода в комнате будет поддерживаться на уровне его концентрации в наружном воздухе, а концентрация углекислого газа не превысит 0,1\% [7], что допустимо для помещений с продолжительным пребыванием людей [8]. Роль вентиляции как универсального механизма регулировании влажности и способа поддержания её нормативных значений в помещении весьма сомнительна по той простой причине, что в зимнее время вентиляция будет приводить к чрезмерной осушке внутреннего воздуха, а в летнее - к увлажнению. Принятые в исследованиях внутренние выделения водяного пара в модельной комнате составляют постоянную величину $\sigma \approx 70$ нл/час (нл - нормальный литр, это такое количество вещества газа, которое займёт один литр при нормальных условиях: давление 101,3 кПа, температура $0{ }^{\circ} \mathrm{C}$ ) и складываются из выделений пара постоянно находящимся в ней человеком на уровне 50 нл/час (дыхание и выделения через кожу) и других возможных дополнительных паровыделений на уровне 20 нл/ час. Дополнительные паровыделения могут быть связаны с тем, что в комнате периодически проводится влажная уборка, могут находиться домашние животные, растения и какие-либо предметы выделяющие влагу, еда, напитки, аквариум и пр.

Для расчётов влажностного режима в комнате использована физико-математическая модель, краевая задача которой для нестационарного переноса водяного пара в объёме комнаты и воды в сорбенте имеет следующий вид:

$$
\begin{aligned}
& \left\{\begin{array}{c}
V \frac{\partial c}{\partial \tau}=Q c_{i m}-Q c+\sigma+S_{c m} \cdot J_{w}, \\
\frac{\partial a}{\partial \tau}=-D \frac{\partial^{2} a}{\partial x^{2}}
\end{array}\right. \\
& \left.\frac{\partial a}{\partial x}\right|_{x=\sigma}=0, \\
& J_{w}=-\left.D \frac{\partial a}{\partial x}\right|_{x=0}=\Pi\left[P(c)-\left.P(a)\right|_{x=0}\right], \\
& a_{t=0}=a_{0}, \\
& \left.\right|_{r=0}=c_{0} .
\end{aligned}
$$

Здесь $V$ - объем комнаты, $\mathrm{m}^{3} ; \tau-$ время, $\mathrm{c} ; c=c(\tau)-$ концентрация водяного пара в комнате, кг $/ \mathrm{m}^{3} ; c_{\text {in }}=c_{\text {in }}(\tau)$ - концентрация водяного пара в вентиляционном воздухе,

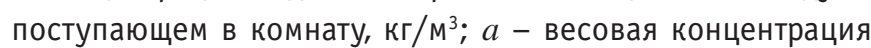

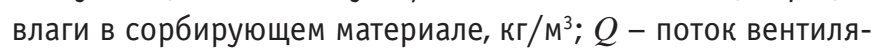

ционного воздуха, нм³ $/$; $\sigma$ - функция источника выделяемого водяного пара, кг/с (внутренние выделения водяного пара); $S_{\text {ст }}$ - площадь сорбирующей водяной пар поверхности, $\mathrm{M}^{2} ; J_{\mathrm{w}}$ - плотность потока водяного пара, выделяемого или поглоща-

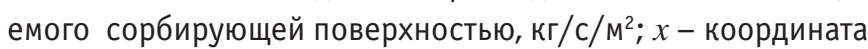
от внутренней поверхности вглубь сорбирующего слоя, м; $D$ - коэффициент диффузии влаги внутри сорбирующего материала, м² $^{2}$; П - паропроницаемость покрытия сорбирующего материала, кг/Па $/ \mathrm{m}^{2} / \mathrm{c} ; P(c)$ - парциальное давление водяного пара в воздухе комнаты, Па; $P(a)$ - равновесное парциальное давление водяного пара в воздухе, соответствующее текущей концентрации влаги в приповерхностном слое сорбирующего материала (зависимость, обратная изотерме сорбции), Па; $a_{0}$ - начальная концентрация влаги в сорбенте,

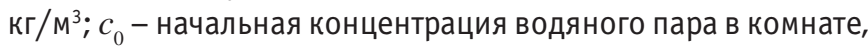
кг $/ \mathrm{m}^{3} ; \delta$ - толщина слоя сорбирующего материала, м.

Краевая задача (1-5) записана для следующих условий:

- в комнате имеет место идеальное смешение, то есть выравнивание концентрации водяного пара по всему объёму. Для выбранных параметров помещения и воздухообмена $\left(V=75\right.$ м³ $^{3} Q=30$ м³ час и характерный размер $L=5$ м) при нормируемой ГОСТ 30494-2011 и СанПиН 2.1.2.2645-10 оптимальной подвижности воздуха $u=0,15$ м/с характерное время воздухообмена $V / Q$ почти в триста раз превышает время конвективного переноса $L / u$, то есть за цикл воздухообмена фактически происходит полное перемешивание воздуха;

- процесс проникновения (сорбции) паров воды в сорбирующий материал в силу того, что стены являются плоскими и имеют сравнительно большую площадь, является практически одномерным.

В качестве сорбента водяного пара рассмотрена деревянная обшивка внутренней поверхности стен (или просто стена, выполненная из дерева). Коэффициент диффузии влаги в дереве принят равным $D=0,5 \cdot 10^{-9} \mathrm{~m}^{2} /$ с что соответствует поперечному коэффициенту диффузии (поперёк волокон) для хвойных пород (например, в монографии [9] приведено значение тангенциального коэффициента диффузии $D=1,89$ - $10^{-9} \mathrm{~m}^{2} /$ с который в несколько раз превышает величину поперечного коэффициента диффузии). Обратная изотерма сорбции взята следующей:

$P(a)=2,3627 \cdot 10^{-3} a^{3}-2,65699 \cdot 10^{-1} a^{2}+9,91432 a-24,4501$, (6) и получена путём обработки данных диаграмм равновесной влажности древесины [10] для температуры $t_{\mathrm{B}}=+20^{\circ} \mathrm{C}$.

С использованием физико-математической модели были выполнены три базовых расчёта вероятных прогнозируемых влажностных режимов жилой комнаты.

Режим 1: Отапливаемое вентилируемое, но не эксплуатируемое помещение (нет источников паровыделения). Сорбция паров воды отсутствует. Влажностный режим помещения определяется вентиляцией;

Режим 2: Отапливаемое, вентилируемое и эксплуатируемое помещение. Сорбция паров воды отсутствует. В расчётах 
определяется дополнительный вклад внутренних выделений паров воды на влажностный режим помещения;

Режим 3: Добавлена сорбция/десорбция паров воды внутренними поверхностями стен и определяется её влияние на влажностный режим помещения.

Расчёты режима 3 проведены на примере использовании в помещении внутренней обшивки стен сорбирующими влагу деревянными панелями с паропроницаемым покрытием. Толщина панелей составляет $\delta \geq 0,1$ м, что соответствует максимальной сорбции паров воды (постоянная времени для диффузии влаги при такой толщине более 180 дней, за которые реализуется полугодовой цикл сезонного тепловлажностного изменения внешней атмосферы). Паропроницаемость покрытия деревянных панелей положена $\Pi=10^{-5}$ кг/Па $/ \mathrm{m}^{2} /$ с, что практически не оказывает сопротивления проникновению пара из воздуха.

Каждый из расчётов проведён для двухгодичного цикла эксплуатации комнаты. В качестве температурно-влажностныххарактеристик внешнего атмосферного воздуха использованы переработанные архивные данные метеостанции (WMO ID) 27612 (Москва, ВВЦ) за 2013 год с достаточно подробной дополнительной детализацией в пределах каждых суток. Среднесуточные значения температуры и влажности по использованным архивным данным приведены на рисунке 1.

Архивные данные позволяют получить точную трёхчасовую детализацию температуры и относительной влажности. Более подробная детализация во времени, необходимая в расчётах, выполнена с помощью линейной интерполяции.

За начало отсчёта времени принято 00:00 часов 01 января первого расчётного года. Второй год по температурно-влажностному режиму наружной атмосферы полностью повторяет первый.

Результаты расчётов изменения относительной влажности жилой комнаты в течение двухгодичного цикла для каждого из режимов представлены на рисунке 2. На графиках также используются среднесуточные значения относительной влажности. При расчётах в качестве начальных условий заданы $a_{0}$ $=40 \mathrm{\kappa r} / \mathrm{m}^{3}$, что соответствует долго эксплуатируемой в сухих условиях древесине, и $c_{0}=9,3 \cdot 10^{-3} \mathrm{kг} / \mathrm{m}^{3}$ (относительная

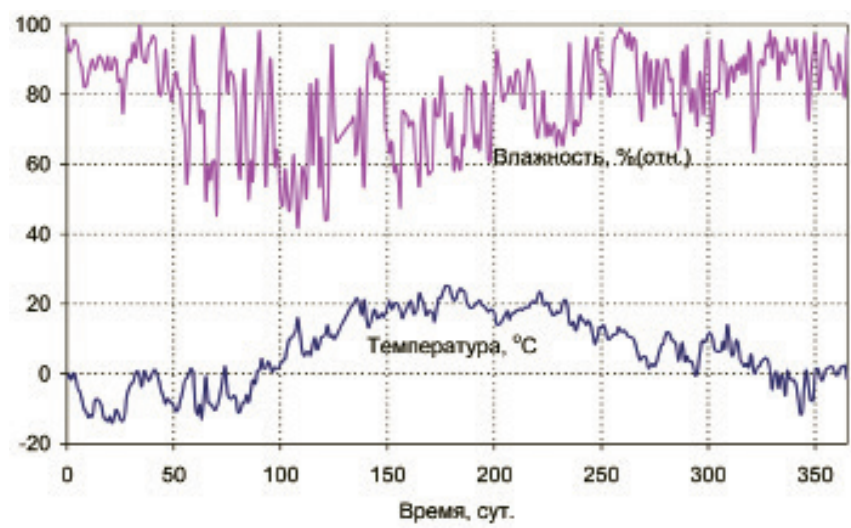

Рис. 1. Температурно-влажностные характеристики атмосферного воздуха влажность помещения равна 50\%). Горизонтальными штриховыми линиями отмечены две границы: нижняя - граница оптимальной влажности для всего года по ГОСТ 30494-2011 [30\% (отн.)] и верхняя - граница допустимой влажности для тёплого периода [65\% (отн.)].

Графики, приведённые на рисунке 2, позволяют установить следующие основные закономерности изменения прогнозируемой величины относительной влажности жилой комнаты в зависимости от режима её эксплуатации и от сезонного фактора, а также соответствие величины влажности требованиям нормативных документов.

Первое, на что следует обратить внимание, это то, что начальные условия $a_{0}$ и $c_{0^{\prime}}$ принятые в расчётах, перестают оказывать влияние на результаты буквально через несколько суток и второй расчётный год по динамике изменения относительной влажности практически полностью совпадает с первым.

Полученные в расчётах общие закономерности динамики поведения относительной влажности без учёта сорбции (режим 1 и режим 2) имеют следующие характерные особенности:

- как и следовало ожидать, в холодный период года относительная влажность имеет самые низкие величины, значительно выходящие за пределы её нормативных значений, причём дополнительные внутренние влаговыделения (человек и пр.) приводят к заметному подъёму её уровня;

- полученная в расчётах ожидаемая средняя влажность в холодный период (январь - март) составляет около 15\% без учёта влаговыделений, и 20-25\% с их учётом, а в период с ноября по декабрь соответственно 30\% и 35-40\%. То есть, другими словами, начало холодного периода вплоть до января месяца для жилого помещения практически соответствует нормативам по величине относительной влажности, а, начиная с января, для поддержания её нормативных значений может понадобиться дополнительное увлажнение помещения;

- в тёплый период времени без учёта сорбции ожидаемая относительная влажность практически всегда превышает допустимую нормативную величину $65 \%$, причём присутствие в комнате человека и наличие других источников влаговы-

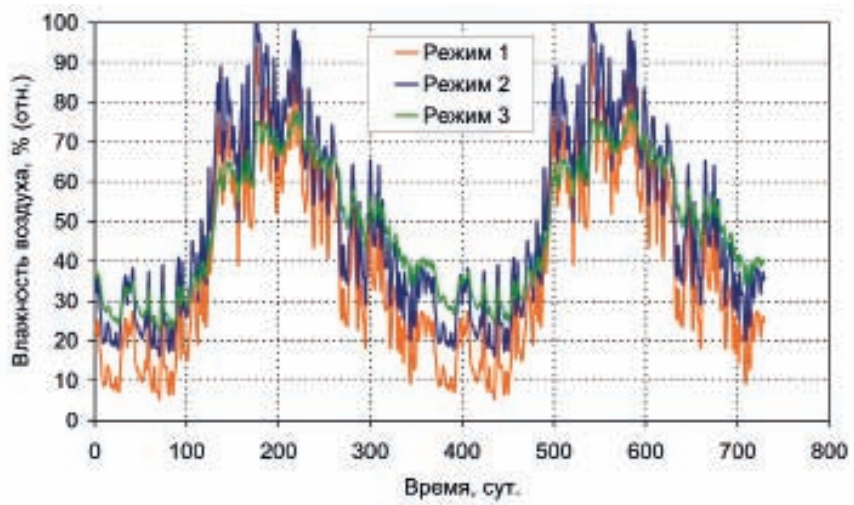

Pис. 2. Относительная влажность комнаты, эксплуатируемой в различных режимах 
деления может привести к тому, что в отдельные периоды влажность может подняться до уровня, близкого к $100 \%$. Увеличение вентиляционного потока способно снизить величину влажности, но всё равно её ожидаемое значение окажется на уровне $70-80 \%$ (см. рис. 1 ).

Посмотрим теперь, как влияет на влажность эффект сорбции паров воды. Оказывается, что если ёмкость сорбента (толщина его слоя) достаточно велика, то, как следует из рисунка 2, этого может оказаться вполне достаточным для обеспечения нормативного влажностного режима в течение большей части года. В холодный период средняя влажность составляет около $30 \%$ за январь-март и более $40 \%$ - на ноябрь-декабрь. В тёплый период влажность не поднимается более 75\% и может превысить нормативное значение 65\% фактически только летом. Главным здесь является также то, что демпфирующие свойства сорбента в виде дерева настолько эффективны, что способны заметно погасить влияние значительных колебаний влажности наружного воздуха. Например, в период от 180 до 183 суток в наружном воздухе амплитуда среднесуточных изменений влажности составила $\Delta \varphi \approx 14 \%$ (см. рис. 1.), соответствующая ей расчётная амплитуда для случая, когда сорбция влаги отсутствует, также была около 14\%, но при наличии сорбирующего материала она составляет величину всего около $3 \%$ (см. рис. 2.).

Таким образом, на примере облицовки из дерева выше было показано, что за счёт сорбции-десорбции паров воды в сорбент достаточно большой ёмкости в общем случае возможно существенное снижение колебаний относительной влажности внутри жилого помещения в течение всего года и приближение её значений к нормативным величинам. Показанная выше величина относительной влажности 75\% для летнего периода является предельной, поскольку она получена в условиях достаточно толстого слоя древесины и практически нулевого сопротивления паропроницанию его покрытия.

Посмотрим теперь, каким параметрам должна удовлетворять сорбирующая поверхность для эффективного регулирования влажности. На рисунке 3 приведена зависимость

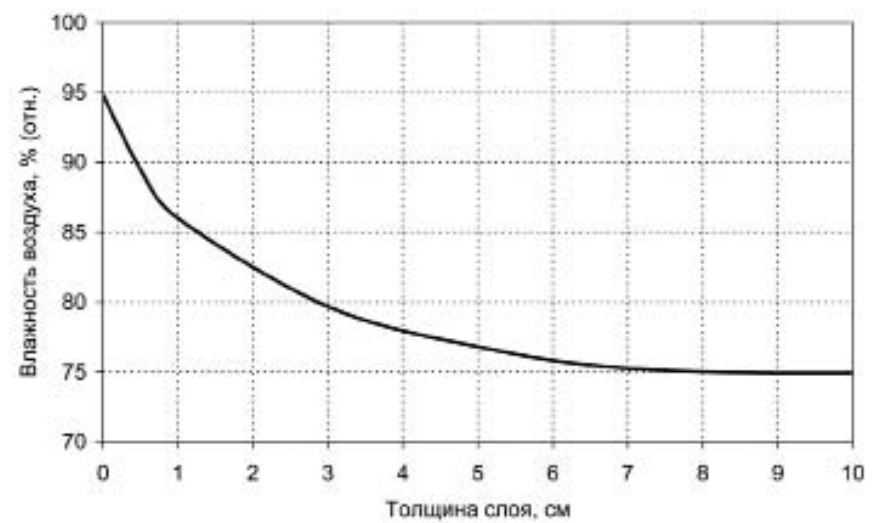

Pис. 3. Относительная влажность воздуха в комнате на 180-й день и 545-й день для двухлетнего периода (180-й день для второго года) в зависимости от толщины деревянной облицовки относительной влажности в комнате от толщины деревянной обшивки. Расчёты выполнены для одного из наиболее неблагоприятных дней, когда среднесуточная относительная влажность в комнате может значительно превосходить её нормативное значение $(65 \%)$ в летний период. Таким днём является 180-й день для первого года или 545-й для двухлетнего периода (180-й для второго года) - середина лета. Из графика видно, что для дерева достаточно высокая стабилизация влажностного режима в комнате будет иметь место при толщине его слоя, начиная уже с 3-х см, а при 5-6 см и выше толщина слоя сорбента уже практически не влияет на изменения влажности. Примем за основу толщину, равную 5 см. Расчёты показывают, что при такой толщине в течение годового цикла средняя по толщине концентрация влаги в древесине изменяется во времени от $\bar{a}=30 \mathrm{kг} / \mathrm{m}^{3}$ в январе-марте до $\bar{a}=80$ кг/м³ в июле-сентябре. Влагосодержание на единицу площади деревянной стенки составляет соответственно от $m_{\mathrm{s}}=1,5$ до $m_{\mathrm{s}}=4,0 \mathrm{kr} / \mathrm{m}^{2}$. Максимальное значение приходится на середину августа месяца. При этом содержание паров воды в воздухе на всю комнату (объем 75 $\mathrm{m}^{3}$ ) колеблется от 0,32 до 1,1 кг, а удельное влагосодержание на единицу площади сорбирующей стены - от $m_{\mathrm{w}}=0,005$ до $m_{\mathrm{w}}=0,018 \mathrm{\kappa г} / \mathrm{m}^{2}$.

Исходя из полученных для деревянной облицовки величин можно ввести обобщённый параметр, характеризующий условие эффективной сорбционной стабилизации влажностного режима в помещениях, записанный в виде отношения наибольшего влагосодержания сорбирующего материала к наибольшему влагосодержанию внутреннего воздуха, приходящегося на единицу поверхности сорбирующего материала:

$$
\Psi=m_{s} / m_{w} \approx 222 M^{-1} .
$$

Величина параметра (7) не зависит от конкретной геометрии комнаты (её объёма, площади сорбирующей облицовки) и может быть использована при расчётах систем стабилизации влажности на основе сорбентов (выбор материала по его сорбционной способности, определение его площади и толщины). При таких расчётах единственным ограничи-

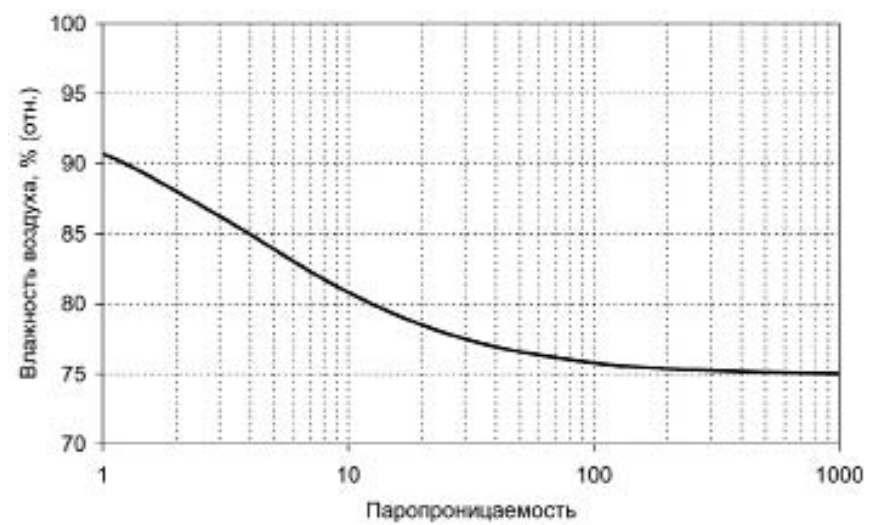

Рuc. 4. Относительная влажность воздуха в комнате на 180-й день и 545-й день для двухлетнего периода (180-й день для второго года) в зависимости от паропроницаемости покрытия деревянной облицовки П $110^{10} \mathrm{\kappa} / \Pi а / \mathrm{m}^{2} / \mathrm{c}$ 
тельным условием является то, что коэффициент диффузии водяного пара должен иметь порядок величины, близкий к дереву. Такими свойствами обладают многие используемые в строительстве материалы, в том числе обладающие высокими сорбционными свойствами, например, волокнистые листовые материалы с внедрёнными сорбентами на основе солей металлов и силикагелей [11]. При использовании вышеуказанного обобщённого параметра (7) удельное влагосодержание внутреннего воздуха $m_{\text {w }}$ должно быть рассчитано для относительной влажности на уровне $75 \%$ (см. графики на рис. 3.).

Определим теперь требования к паропроницаемости П покрытия сорбционного материала. На рисунке 4 приведены расчётные данные для относительной влажности в комнате в зависимости от паропроницаемости. Расчёты выполнены для тех же условий, что и на рисунке 3.

В расчётах толщина слоя дерева выбрана достаточно большой, для того чтобы условия соответствовали максимальному его увлажнению. Как видно из графика, покрытие сорбционного слоя оказывает заметное влияние на стабилизацию влажностного режима в помещении в тех случаях, когда его паропроницаемость падает до величины ниже $\Pi \leq$ $10 \cdot 10^{-10} \kappa г / \Pi а / \mathrm{m}^{2} / \mathrm{c}$.

Для сравнения: паропроницаемость картона толщиной 0,5 мм составляет 300・10-10, паропроницаемость слоя лака толщиной 10 мкм составляет 2,5•10-13, а паропроницаемость полиэтилена толщиной 50 мкм составляет $1 \cdot 10^{-10}($ кг/Па/ $/ 2 / \mathrm{c})$. Это означает, что для эффективной работы сорбционного слоя его покрытие не должно содержать полимерных плёночных компонентов и красок, но использование обоев, тканей и пр. может оказаться вполне достаточным. Требования по паропроницаемости могут оказаться менее жёсткими только для сорбентов с более высокими коэффициентами диффузии влаги в сорбенте [см. уравнение (3)].

Обобщая полученные результаты, можно сказать следующее:

Разработанная физико-математическая модель позволяет рассчитывать влажностный режим помещения в нестационарных условиях, приближенных к реальным. Модель учитывает поступление и удаление паров воды с вентиляционным воздухом, выделения водяного пара внутренними источниками и также его сорбцию-десорбцию внутренними материалами. Использованная модель может применяться для помещений с непостоянным пребыванием людей (жилые и общественные здания). Модель также применима и для моделирования массопереноса различных примесей в помещении, таких как формальдегид, фенол, углекислый газ и др.

На примере отапливаемого жилого помещения проанализирован его годовой влажностный режим в различных случаях и установлено, что наличие сорбционного слоя существенным образом влияет на относительную влажность, приближая её к нормативным значениям. Демпфирующий эффект обеспечивается значительной влагоёмкостью сорбирующего материала, в сотни раз превосходящей влагоёмкость внутреннего воздуха. Значимая инертность сорбента по парам воды позволяет сгладить как суточные, так и сезонные колебания влажности в помещении. В холодный период года влажность практически не опускается ниже нормативных величин, а в тёплый период превышение её допустимых значений незначительно и носит ограниченный по времени характер.

На примере деревянной обшивки внутренних стен установлено, что для реализации положительных свойств сорбционного эффекта достаточно 5 см её толщины. Дальнейшее увеличение толщины обшивки не приводит к значимым изменениям параметров внутреннего воздуха.

Что касается проектирования систем для стабилизации влажности в отапливаемых помещениях на основе сорбирующих материалов, отличных от дерева (выбор сорбента, требуемая площадь и толщина слоя), то в качестве оценочного критерия здесь может быть использован следующий: основным исходным параметром при проектировании может быть удельная влагоёмкость сорбента, приходящаяся на единицу площади его поверхности. Как показано, эта величина должна более чем в 200 раз превосходить удельное влагосодержание воздуха в помещении при относительной влажности 75\%, приходящееся также на единицу площади сорбирующего материала.

Установленные критерии по паропроницаемости материалов покрытия сорбирующего слоя показывают, что применение лакокрасочных укрывных материалов и полимерных плёнок приводит к потере демпфирующих сорбционных свойств, в то время как покрытие бумажными обоями или аналогичными по паропроницаемости слоями практически не оказывает негативного влияния.

\section{Лuтература}

1. Куприянов, В.Н. Паропроницаемость и проектирование ограждающих конструкций / В.Н. Куприянов, И.Ш. Сафин // Academia. Архитектура и строительство. - 2010. - № 3. - С. 385-390.

2. Куприянов, В.Н. К вопросу о паропрницаемости ограждающих конструкций / В.Н. Куприянов, И.Ш. Сафин, А.Г. Хабибуллина // Academia. Архитектура и строительство. 2009. - № 5. - С. 504-507.

3. Шеnc, P.A. Теплозащитные свойства ограждений с учетом прогнозируемых условий эксплуатации / Р.А. Шепс, Т.В. Щукина // Жилищное строительство. - 2015. - № 7. - С. 29-30.

4. Бородин, А.И. Учёт влияния влажности среды при расчете термического сопротивления ограждающих конструкций / А.И. Бородин, 3.Б. Чапанов // Известия высших учебных заведений. Строительство. - 2009. - № 7. - С. 44-43.

5. Ельчищева, Т.Ф. Определение влажностного режима помещений зданий при наличии в стеновом материале гигроскопических солей / Т.Ф. Ельчищева // Строительные материалы. - 2017. - № 6. - С. 14-18.

6. Гагарин, В.Г. К вопросу о назначении расчётной влажности строительных материалов по изотерме сорбции / В.Г. 
Гагарин, П.П. Пастушков, Н.А. Реутова // Строительство и реконструкция. - 2015. - № 4. - С. 152-155.

7. Левин, Е.В. К вопросу об использовании мембранных технологий для создания дыхательных атмосфер / Е.В. Левин, А.Ю. Окунев // Academia. Архитектура и строительство. 2010. - № 3. - С. 512-520.

8. Нимич Г.В. Современные системы вентиляции и кондиционирования воздуха / Г.В. Нимич, В.А. Михайлов, Е.С. Бондарь. - Киев: ИВИК, 2003. - 626 с.

9. Чудинов, Б.С. Вода в древесине / Б.С. Чудинов. - Новосибирск: Наука, 1984. - 270 с.

10. Серговский, П.С. Гидротермическая обработка и консервирование древесины / П.С. Серговский. - М.: Лесная промышленность, 1975. - 400 с.

11. Волокнистый листовой материал для удаления влаги из воздуха / М.А. Ульянова, А.С. Гурова, Н.П. Юркина [и др.] // Вестник ТГТУ. - 2009. - Том 15. - № 1. - С. 106-112.

\section{Literatura}

1. Kupriyanov V.N. Paropronitsaemost' i proektirovanie ograzhdayushhih konstruktsij / V.N. Kupriyanov, I.Sh. Safin // Academia. Arhitektura i stroitel'stvo. - 2010. - № 3. - S. 385-390.

2. Kupriyanov V.N. K voprosu o paroprnitsaemosti ograzhdayushhih konstruktsij / V.N. Kupriyanov, I.Sh. Safin, A.G. Habibullina // Academia. Arhitektura i stroitel'stvo. 2009. - № 5. - S. 504-507.

3. Sheps R.A. Teplozashhitnye svojstva ograzhdenij s uchetom prognoziruemyh uslovij ekspluatatsii / R.A. Sheps, T.V. Shhukina // Zhilishhnoe stroitel'stvo. - 2015. - № 7. - S. 29-30.
4. Borodin A.I. Uchet vliyaniya vlazhnosti sredy pri raschete termicheskogo soprotivleniya ograzhdayushhih konstruktsij / A.I. Borodin, Z.B. Chapanov // Izvestiya vysshih uchebnyh zavedenij. Stroitel'stvo. - 2009. - № 7. - S. 44-43.

5. El'chishheva T.F. Opredelenie vlazhnostnogo rezhima pomeshhenij zdanij pri nalichii $\vee$ stenovom materiale gigroskopicheskih solej / T.F. El'chishheva // Stroitel'nye materialy. - 2017. - № 6. - S. 14-18.

6. Gagarin V.G. K voprosu o naznachenii raschetnoj vlazhnosti stroitel'nyh materialov po izoterme sorbtsii / V.G. Gagarin, P.P. Pastushkov, N.A. Reutova // Stroitel'stvo i rekonstruktsiya. - 2015. - № 4. - S. 152-155.

7. Levin E.V. K voprosu ob ispol'zovanii membrannyh tehnologij dlya sozdaniya dyhatel'nyh atmosfer / E.V. Levin, A.Yu. Okunev // Academia. Arhitektura i stroitel'stvo. - 2010. - № 3. - S. 512-520.

8. Nimich G.V. Sovremennye sistemy ventilyatsii i konditsionirovaniya vozduha / G.V. Nimich, V.A. Mihajlov, E.S. Bondar'. - Kiev: IVIK, 2003. - 626 s.

9. Chudinov B.S. Voda v drevesine / B.S. Chudinov. Novosibirsk: Nauka, 1984. - $270 \mathrm{~s}$.

10. Sergovskij P.S. Gidrotermicheskaya obrabotka i konservirovanie drevesiny / P.S. Sergovskij . - M.: Lesnaya promyshlennost', 1975. - $400 \mathrm{~s}$.

11. Voloknistyj listovoj material dlya udaleniya vlagi iz vozduha / M.A. Ul'yanova, A.S. Gurova, N.P. Yurkina [i dr.] // Vestnik TGTU. - 2009. - Tom 15. - № 1. - S. 106-112.

Левин Евгений Владимирович, 1952 г.р. Москва. Кандидат физико-математических наук, старший научный сотрудник. Главный научный сотрудник «ФГБУ «Научно-исследовательский институт строительной физики РААСН» (127238, Москва, Локомотивный проезд, 21. НИИСФ РААСН). Сфера научных интересов: теплофизика, молекулярная физика, тепло-массообменные процессы, мембранные газоразделительные процессы, теория и практика использования инфракрасного излучения. Автор более 100 научных публикаций. Тел.: 8 (495) 482-38-92; +7 (916) 657-31-93. E-mail: aqwsrv@list.ru.

Окунев Александр Юрьевич, 1981 г.р. (Москва). Кандидат физико-математических наук. Главный научный сотрудник «ФГБУ «Научноисследовательский институт строительной физики РААСН» (127238, Москва, Локомотивный проезд, 21. НИИСФ РААСН). Сфера научных интересов: теплофизика, молекулярная физика, тепло-массообменные процессы, теория и практика использования инфракрасного излучения. Автор более 100 научных публикаций. Тел.: 8 (495) 482-38-92; +7 (926) 336-18-35. E-mail: okunevay@gmail.com.

Evgeny Vladimirovich Levin, born in 1952 (Moscow). Candidate of Physical and Mathematical Sciences, Senior Researcher. Chief Researcher at Scientific-Research Institute of Building Physics of RAACS (127238, Moscow, Lokomotivny proezd, 21. NIISF RAASN). Research interests: thermal physics, molecular physics, heat and mass transfer processes, membrane gas separation processes, theory and practice of using infrared radiation. The author of more than 100 scientific publications. Tel: $+7(495)$ 482-38-92; +7 (916) 657-31-93. E-mail: aqwsrv@list.ru.

Okunev Alexander Yurievich, born in 1981 (Moscow). Candidate of Physical and Mathematical Sciences. Chief Researcher at Scientific-Research Institute of Building Physics of RAACS (127238, Moscow, Lokomotivny proezd, 21. NIISF RAASN). Research interests: thermal physics, molecular physics, heat and mass transfer processes, theory and practice of using infrared radiation. The author of more than 100 scientific publications. Tel: +7 (495) 482-38-92; +7 (926) 336-18-35. Email: okunevay@gmail.com. 